\title{
Tropical Rainfall Measuring Mission
}

NASA Goddard Distributed Active Archive Center • Code 902 • Greenbelt, MD 20771

TRMM images are available from: http://trmm.gsfc.nasa.gov/
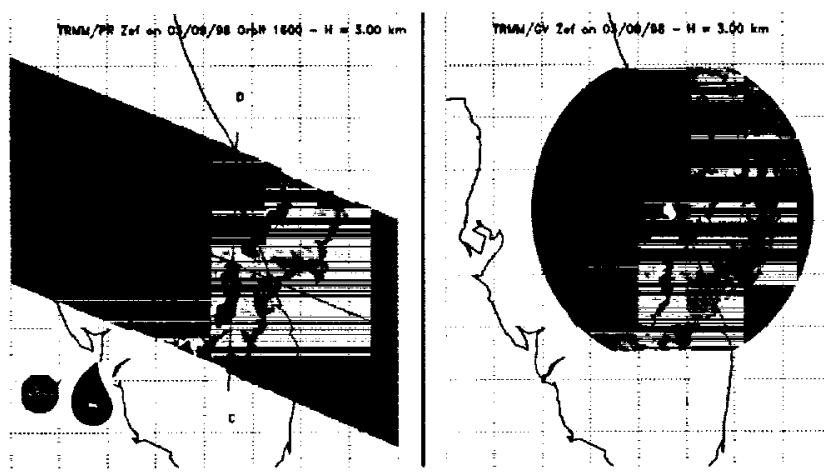

Comparison of horizontal rain rate distribution at $3 \mathrm{~km}$ and vertical rain rate profile derived from the TRMM precipitation radar (PR 2A25) with the ground radar
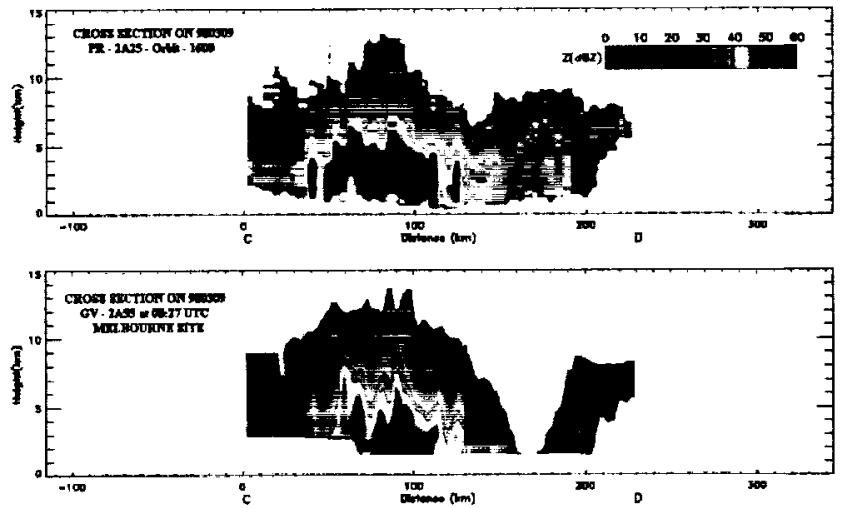

(GV 2A55) when the TRMM satellite passed over Melbourne, Florida on March 9, 1998. (Figures courtesy of Dr. Kummerow et al.)

Hurricane Bonnie over the North Carolina coast, August 26, 1998. This image combines precipitation radar (PR) and visible and infrared sensor (VIRS) data. The narrow light-colored band is the PR swath, with progressively higher rain intensity in green, yellow, and orange.
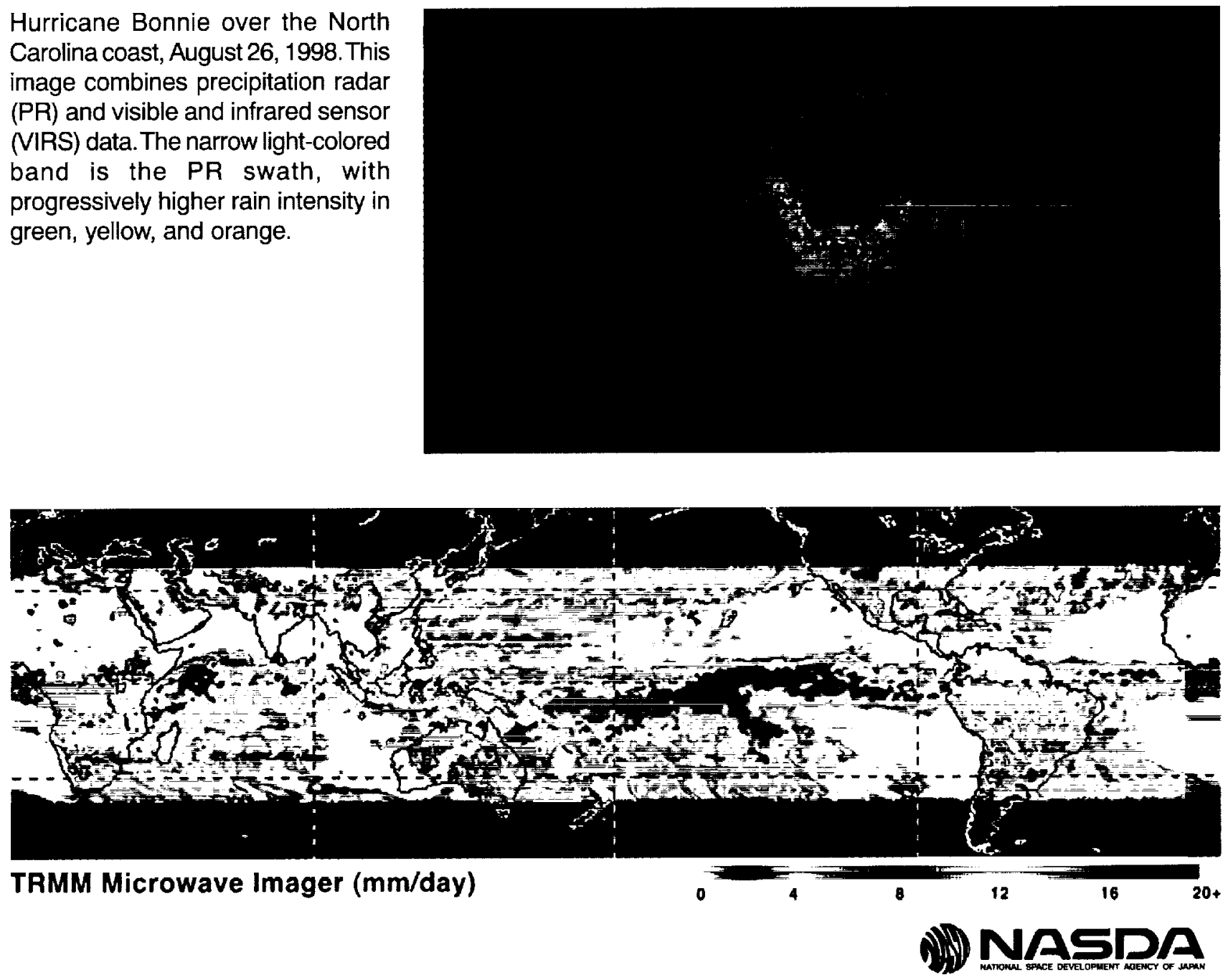
Tropical rainfall affects the lives and economies of a majority of the Earth's population. Tropical rain systems, such as hurricanes, typhoons, and monsoons, are crucial to sustaining the livelihoods of those living in the tropics. Excess rainfall can cause floods and great property and crop damage, whereas too little rainfall can cause drought and crop failure.

The latent heat release during the process of precipitation is a major source of energy that drives the atmospheric circulation. This latent heat can intensify weather systems, affecting weather thousands of kilometers away, thus making tropical rainfall an important indicator of atmospheric circulation and short-term climate change.

Tropical forests and the underlying soils are major sources of many of the atmosphere's trace constituents. Together, the forests and the atmosphere act as a water-energy regulating system. Most of the rainfall is returned to the atmosphere through evaporation and transpiration, and the atmospheric trace constituents take part in the recycling process. Hence, the hydrological cycle provides a direct link between tropical rainfall and the global cycles of carbon, nitrogen, and sulfur, all important trace materials for the Earth's system.

Because rainfall is such an important component in the interactions between the ocean, atmosphere, land, and the biosphere, accurate measurements of rainfall are crucial to un-

\section{TRMM Orbit and Instruments}

The TRMM satellite's low inclination (35 degrees), non-sunsynchronous, and highly precessing orbit allows it to fly over each position on the Earth's surface at a different local time each day. This kind of sampling allows the examination of derstanding the workings of the Earth-atmosphere system. The large spatial and temporal variability of rainfall systems, however, poses a major challenge to estimating global rainfall. So far, there has been a lack of rain gauge networks, especially over the oceans, which points to satellite measurement as the only means by which global observation of rainfall can be made.

The Tropical Rainfall Measuring Mission (TRMM), jointly sponsored by the National Aeronautics and Space Administration (NASA) of the United States and the National Space Development Agency (NASDA) of Japan, provides visible, infrared, and microwave observations of tropical and subtropical rain systems. The satellite observations are complemented by ground radar and rain gauge measurements to validate satellite rain estimation techniques. Goddard Space Flight Center's involvement includes the observatory, four instruments, integration and testing of the observatory, data processing and distribution, and satellite operations. TRMM has a design lifetime of three years.

Data generated from TRMM and archived at the GDAAC are useful not only for hydrologists, atmospheric scientists, and climatologists, but also for the health community studying infectious diseases, the ocean research community, and the agricultural community.

the diurnal cycle of precipitation. The orbit is maintained at approximately $350 \mathrm{~km}$. The characteristics of the three rain instruments and associated science applications are shown in the following table.

\section{Precipitation Radar (PR)}

\begin{tabular}{ll}
$\begin{array}{l}\text { Frequency } W \text { ave- } \\
\text { length }\end{array}$ & $\begin{array}{l}\text { Vertical polarization: } \\
13.8 \mathrm{GHz}\end{array}$ \\
& \\
\hline Scanning Mode & Cross track
\end{tabular}

\begin{tabular}{l} 
Ground Resolution $\quad 4 \mathrm{~km}$ at nadir \\
\hline Swath Width \\
\hline
\end{tabular}

3-D rainfall distribution over Science _ _ both land and oceans, and Applications

\section{TRMM Microwave Imager (TMI)}

Dual polarization:

$10.65,19.35,37, \& 85.5 \mathrm{GHz}$

Vertical polarization: $21 \mathrm{GHz}$

Conical

Ranges from $5 \mathrm{~km}$ at $85.5 \mathrm{GHz}$ to $45 \mathrm{~km}$ at $10 \mathrm{GHz}$

$760 \mathrm{~km}$

Surface rainfall rate, rain type, distribution, and structure
Visible/Infrared
Scanner (VIRS)

$.63,1.6,3.75,10.8, \&$ $12 \mu \mathrm{m}$

Cross track

$2.2 \mathrm{~km}$

$720 \mathrm{~km}$

Cloud coverage, cloud type, cloud top temperature, and precipitation index 
In addition, a Lightning Imaging Sensor (LIS) and a Clouds and Earth's Radiant Energy System (CERES) are carried on the TRMM satellite. The LIS is a calibrated optical sensor operating at 0.7774 micron and observes distribution and variability of lightning. The horizontal resolution of LIS at nadir is $5 \mathrm{~km}$ and the swath width is $590 \mathrm{~km}$. The CERES is a visible/infrared sensor which measures emitted and re- flected radiative energy from the surface of the Earth and the atmosphere and its constituents. The TRMM CERES operates at 0.3 to 5.0 microns in the shortwave range and 8.0 to 12.0 microns in the longwave range. LIS data are available from the Global Hydrology Resource Center (http:// ghrc.msfc.nasa.gov), and CERES data are available from the NASA Langley DAAC (http://eosweb.larc.nasa.gov/).

\section{TRMM Ground Track for $35^{\circ}$ Orbit With Ground Truth Verification Sites}

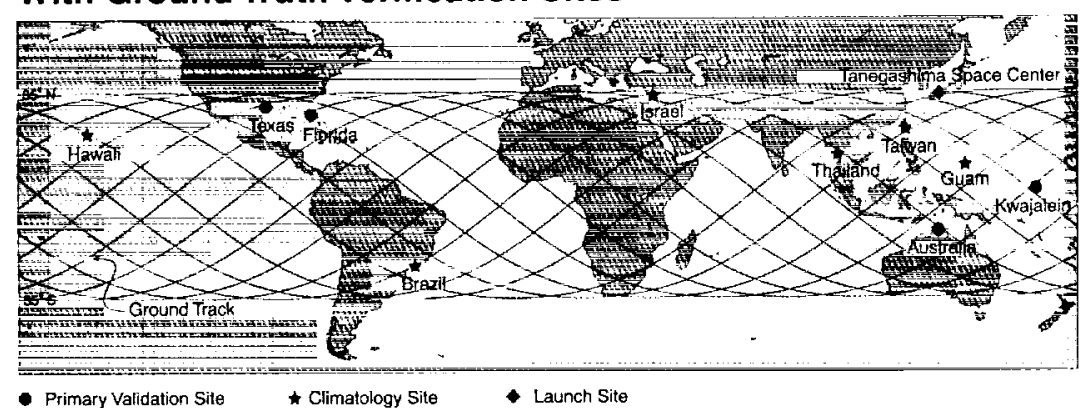

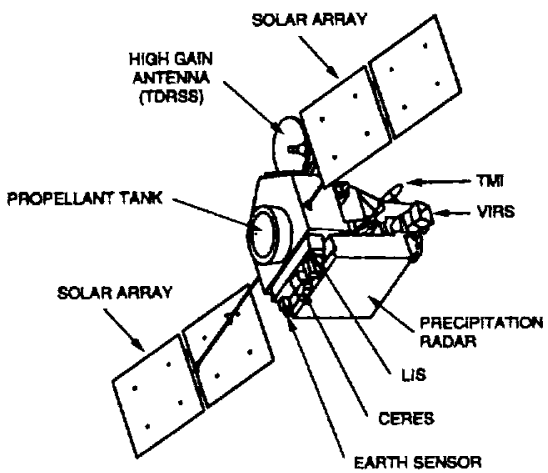

Ground Validation (GV) radar sites include Darwin, Australia; Thailand; Israel; Taiwan; Sao Paolo, Brazil; Guam; Kwajalein; Hawaii; Melbourne, Miami, Key West, and
Tampa Bay in Florida; Lake Charles in Louisiana; and New Braunfels, Corpus Christi, and the Texas A\&M research radar in Texas.

\section{TRMM Science Data Products at the GDAAC}

The GDAAC archives and distributes TRMM standard products, processed from the TRMM science data by the TRMM Science Data and Information System (TSDIS). Level 1 products are the VIRS calibrated radiances, the TMI brightness temperatures, and the PR return power and reflectivity measurements. Level 2 products are derived geophysical parameters (e.g., rain rate and latent heat) at the same resolution and location as those of the Level 1 data. Level 3 products are space-time averaged parameters. Level 4 products are analyzed products or those produced from merging measurements from TRMM and other sources. TRMM standard products are listed in the table on page 4.

Also included as TRMM standard products are surfacebased observations of rainfall from rain gauges and ground radars, which are used to calibrate and validate the satellite measurements.

\section{TRMM Data Access and Services at GDAAC}

TRMM standard products are available to the general public at http://lake.nascom.nasa.gov/data/dataset/TRMM/ index.html. In addition, subsets of the TRMM data are available to facilitate analyses and processing by users, including satellite-ground coincidence subsets, gridded orbital data at various resolutions, parameter subsets, regional subsets, and others as needed. Data related to various TRMM validation experiments are available from http:// daac.gsfc.nasa.gov/CAMPAIGN_DOCS/TRMM_FE/ trmm_fe.html. Data sets are distributed via ftp or sent via tapes.
Potential TRMM data users, especially those with specific needs, are urged to contact the GDAAC Hydrology Data Support Team:

$\begin{array}{ll}\text { Email: } & \text { hydrology@daac.gsfc.nasa.gov } \\ \text { Fax: } & (301) 614-5268\end{array}$

To stay informed about the latest developments in TRMM data products and services at the GDAAC, please visit our Hydrology Web site: http://daac.gsfc.nasa.gov/ CAMPAIGN_DOCS/hydrology/hd_main.html 


\section{TRMM Standard Products}

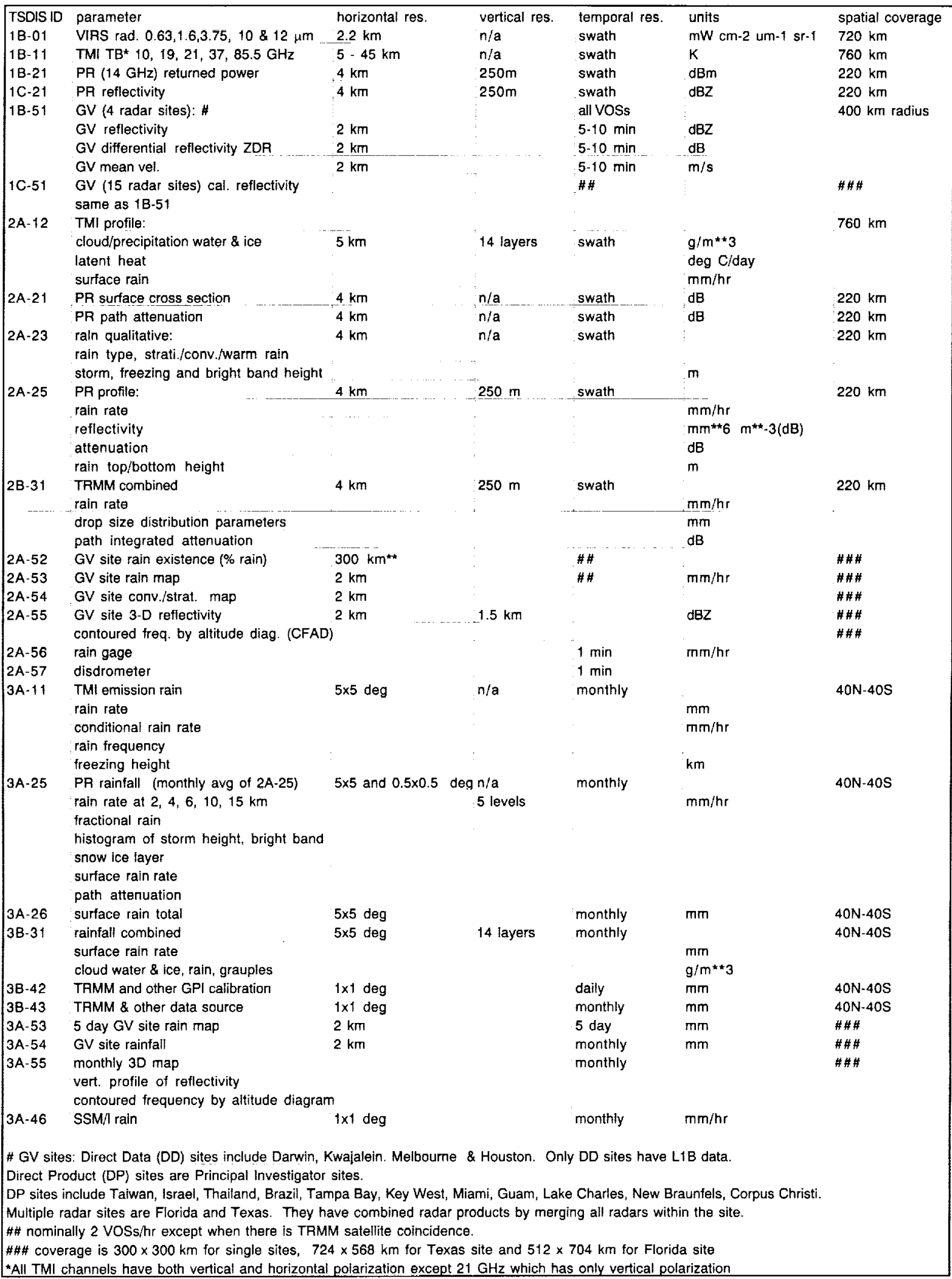

NASA GSFC Distributed Active Archive Center

http://daac.gsfc.nasa.gov/

NP-1998-12-074-GSFC 